\title{
On the other end of research: exploring community-level knowledge exchanges in small-scale fisheries in Zanzibar
}

\author{
Viola Hakkarainen ${ }^{1,2,3} \cdot \operatorname{Tim}$ M. Daw ${ }^{3} \cdot$ Maria Tengö ${ }^{3}$
}

Received: 4 June 2019 / Accepted: 22 October 2019 / Published online: 5 November 2019

(c) The Author(s) 2019

\begin{abstract}
Sustainability science has increasingly adopted more action-oriented approaches in an attempt to mobilise and implement a broad knowledge base to sustain human wellbeing and promote sustainable development. There is an increasing recognition of the importance of knowledge exchange (KE) between scientists and end users of research for enhancing social, environmental and economic impacts of research. Here, we explore the process of KE through close observation of two cases of KE between external $\mathrm{PhD}$ researchers and local actors in small-scale fisheries at the community level in Zanzibar, Tanzania. First, we address context by examining perceptions of research held by actors at community level and patterns of interactions and flows of benefits between external researchers and local actors including fisheries managers, local research institute as well as fishers and traders. Second, we unpack experiences of actors engaged in the cases of KE. The study draws attention to KE processes in the Global South and actors outside decision-making processes in fisheries management. The study concludes that as KE is a complex and dynamic process and that (i) history and relationships between actors shape the outcomes of $\mathrm{KE}$, (ii) KE includes more than knowledge-based processes and outcomes because multiple incentives of different actors shape KE and how it is experiences and (iii) knowledge-based outcomes of KE are complex and unpredictable as different actors create their own meaning from shared information. The results exemplify the inevitably complex and unpredictable nature of KE processes and their outcomes, and provide insight into how KE can contribute to science-society relationships.
\end{abstract}

Keywords Knowledge exchange $\cdot$ Science-society interaction $\cdot$ Knowledge systems $\cdot$ Small-scale fisheries $\cdot$ Zanzibar

\section{Introduction}

Sustainability science scholars have increasingly focused on bridging science and decision making, as this is considered key to sustainability (Cash et al. 2003; Clark et al. 2016;

Handled by Nicola Grigg, Commonwealth Scientific and Industrial Research Organization (CSIRO), Australia.

Electronic supplementary material The online version of this article (https://doi.org/10.1007/s11625-019-00750-4) contains supplementary material, which is available to authorized users.

Viola Hakkarainen

viola.hakkarainen@luke.fi

1 Natural Resources Institute Finland, Latokartanonkaari 9, 00790 Helsinki, Finland

2 University of Helsinki, Viikinkaari 1, PO Box 65, 00014 Helsinki, Finland

3 Stockholm Resilience Centre, Kräftriket 2B, 10405 Stockholm, Sweden
Cornell et al. 2013; van Kerkhoff and Pilbeam 2017). This is based on the normative assumption that research should have impact in society. Sustainability science has even been described as "fundamentally interventionist" (van Kerkhoff and Pilbeam 2017) as it has adopted more action-oriented approaches to enhance the role of science in decisionmaking (Clark et al. 2016; West et al. 2019). Scientists are increasingly participating in activities beyond knowledge production such as multi-way interactions and knowledge co-production with decision makers and other beneficiaries of science (Fazey et al. 2013; Lemos et al. 2018; Singh et al. 2014). Folke et al. (2005) link the shift in researchers' roles to rapid environmental changes, which demands researchers to deliver knowledge to managers instead of maintaining their position as objective and detached specialists.

Critical approaches to understanding the role of science in environmental decision making are concerned with power relations as well as desirability and efficiency of science in decision-making (van Kekhoff and Pilbeam 2017). Western scientific knowledge has a multi-dimensional relationship 
with non-Western contexts, such as the East African fisheries investigated in this paper, playing out in complex and asymmetrical power relations and often in light of colonial history (Hoppers 2002). Accordingly, different kinds of scientific knowledge are situated in specific socio-political and cultural contexts and thus are value-laden in nature (Bäckstrand 2003; Hoppers 2002). Therefore, relationships between research-based knowledge and action are embedded within larger power structures that change over time (van Kerkhoff and Lebel 2006), and understanding these relationships requires examination of the socio-political context in which the generation and use of scientific knowledge are situated (van Kerkhoff and Pilbeam 2017).

These challenges have stimulated a growing literature examining how scientific knowledge bridges to policy arenas (e.g. Cornell et al. 2013; Cvitanovic et al. 2015a, b; Raymond et al. 2010; Roux et al. 2006). The gap between academia and the "real" world is widely recognised as the science-policy or science-practice gap, and discussed, for example in conservation science (e.g. Boreux et al. 2009; Gallo et al. 2009; Kirchhoff et al. 2013; Lemos et al. 2012). However, the metaphor of a science-practice gap has come to be considered as simplistic and problematic, as it ignores conflicting values, complex and dynamic relations and varying capacities that always exists when science and society interact (e.g. Cvitanovic et al. 2015a, b; Toomey 2016; van Kerkhoff and Lebel 2015). Thus, ideas of linear knowledge transfer are increasingly replaced by more complex understandings of knowledge exchange (KE) as a two-way exchange (Fazey et al. 2014, 2013; Roux et al. 2006) that needs to be studied as a process (Fazey et al. 2014). Consequently, a range of obstacles to efficient KE have been identified, including factors such as cultural differences between researchers and decision-makers, different worldviews and perceptions of knowledge and how it can be generated and transmitted, institutional barriers, and mismatches between societal knowledge needs and research design (Cvitanovic et al. 2016; Nguyen et al. 2018; Raymond et al. 2010). Proposed strategies for successful KE thus include engagement of stakeholders from early stages of research process, using third parties such as boundary organisations and knowledge brokers, and long-term knowledge management-often referred to as co-production of knowledge or participatory research (e.g. Cook et al. 2013; Cvitanovic et al. 2016; Phillipson et al. 2012; Reed et al. 2014; West et al. 2019). Guidelines to help researchers navigate the knowledge-action landscape and KE in environmental management are emerging (Nguyen et al. 2017; Reed et al. 2014). They illustrate the need for both theoretically advancing understanding about KE processes and practically guiding researchers in the implementation of KE.

Addressing sustainability in fisheries requires researchers to implement appropriate KE so that a range of different non-academic users are reached (Young et al. 2016b). Literature on KE in fisheries and marine resources has focussed on a narrow policy-science interface, largely in the Global North (Cvitanovic et al. 2015b). Recently, KE literature has expanded to include perceptions of end users of research, outside of formal decision-making processes, e.g. fisherfolk. Further, it draws on sociology of science to identify how normative expectations and knowledge claims may differ among authorities and other stakeholders (Young et al. 2016a). This opens up for further research to understand how $\mathrm{KE}$ in the context of fisheries management may play out in different geographical locations and under different conditions, for example in the Global South, where access to scientific knowledge may be limited and governance structures not so clearly defined (Cvitanovic et al. 2015b). Research by northern researchers in the Global South creates a particular setting for KE, which raises ethical considerations because of the exaggerated power relations and postcolonial contexts.

With this paper, we aim to contribute to sustainability science practice that makes scientific knowledge useable for broader sets of users, and creates conditions for shared learning among different actors, including researchers, in KE processes. More specifically, we add to the emerging literature addressing KE with local resource users in the Global South, by showing the effects of asymmetry between the actors involved in the exchange. We analyse two case studies of KE with local communities of fishers on the Unguja island of Zanzibar, East Africa, and address the context and different experiences and perceptions of the KE processes using a qualitative approach. This study provides empirical evidence of KE in a context in which, despite a vast number of fisheries related research projects, access to scientific knowledge is restricted-among local fishers as well as formal managers. We add to the KE literature by drawing focus on the contextual factors that shape outcomes of KE beyond the specific KE interventions.

\section{Defining knowledge}

We draw from constructive social science epistemology by defining knowledge as justified belief that is used to claim a truth and determined by acceptance of that truth in a particular context (Jacobson 2007; Nonaka et al. 2000; van Kerkhoff and Lebel 2006). Hence, in different contexts, knowledge takes different forms depending on the sets of criteria that the justification is based on (van Kerkhoff and Lebel 2006). According to Tàbara and Chabay (2013), information is turned into knowledge through meaning, which constitutes the possibility to "understand, intervene or resolve particular problems or address particular situations in meaningful or/ and satisfactory ways". Knowledge can thereby be recognized as multidimensional and context dependant, and it is 
embodied in practices, tools, technologies and institutions used by different actors (Cote and Nightingale 2012; Tengö et al. 2017).

\section{An analytic approach for studying interventions of knowledge exchange}

We use three sets of literature in theorising knowledge processes to acknowledge complexity of knowledge processes: knowledge systems (KS), knowledge exchange (KE) and knowledge governance (KG).

Cornell et al (2013) conceptualise knowledge systems consisting of agents, practices and institutions, which construct the use, transfer and production of knowledge. Relationships within knowledge systems shape flows of knowledge, credibility and power (Cornell et al. 2013). Different actors can represent different knowledge systems, so that excluding certain actors can also mean excluding knowledge systems and kinds of knowledge (Tengö et al. 2017). Bridging and collaborating across different knowledge systems can support sustainable management of resources and improve governance (Agrawal 1995; Berkes 2009; Tàbara and Chabay 2013; Tengö et al. 2017). Simultaneously, coupling science with action and making better use of scientific knowledge in decision making is acknowledged as a key to sustainable development (Cash et al. 2003; Clark et al. 2016; Cornell et al. 2013; Fazey et al. 2007; Folke et al. 2005).

Knowledge exchange (KE) is a broad term that refers to "the process of sharing, using, and generating information through various methods appropriate to the context, audience and purpose of communication" (Fazey et al. 2013). $\mathrm{KE}$ includes concepts such as co-production, transfer, storage, transformation, integration and translation of knowledge and social learning (Fazey et al. 2014). KE as a research field is relatively new and it has often been presented as a tool rather than a complex and dynamic process with many uncertainties and interpretations (Cvitanovic et al. 2015a, b; Fazey et al. 2013). Such a perspective show how the ways knowledge is produced, shared and translated, as well as the social context where people learn about new knowledge determines if policy and practice are informed by science (Reed et al. 2014). Therefore, understanding habits and preferences of the actors turning knowledge into action is crucial for improving KE (Young et al. 2016b). Additionally, the concept of knowledge governance (KG) has been proposed to think critically about knowledge-based processes for sustainable development. KG is defined as "the formal and informal rules and conventions that shape the ways we conduct or engage in knowledge processes, such as creating new knowledge, sharing or protecting knowledge, accessing it and applying or using it" (van Kerkhoff 2014; van Kerkhoff and Pilbeam 2017). In this paper, we address this using an analytical approach bringing together conceptualisations of knowledge processes in knowledge systems, knowledge exchange and knowledge governance literature.

According to Cash et al.'s (2003) work on KS, actors' perceptions of the credibility, legitimacy and salience of knowledge determine if knowledge will feed into action, particularly in interactions between science and policy. In other theoretical conceptualisations of $\mathrm{KE}$, relevance, legitimacy and accessibility are named as factors that shape how knowledge translates into policy and action (Contandriopoulos et al. 2010; Reed et al. 2014). Table 1 presents how the three sets of literature talk about these central concepts. Examination of the different definitions reveals that the concepts are overlapping and not fixed across the KE and KS literatures. Legitimacy and credibility are similar in nature, particularly in the KE literature, and salience and relevance are used as synonyms across literatures. KE has the additional focus on accessibility, which does not feature in the KS work. Kerkhoff and Pilbeam (2017) instead operationalise KG to study the socio-political context utilising Cash et al.'s conceptualisation of KS.

Figure 1 illustrates the analytic approach used in the study. Interactions between scientific and local knowledge systems in KE interventions are embedded in a KG context, and utilisation of research is determined by perceptions of relevance (as usefulness and actionability of information), legitimacy (as representativeness of different views), credibility (as trustworthiness of information) and accessibility (as availability and access to information) of new information. In this study, KG is used to emphasise the importance of contextual factors that shape KE and situate the interventions in greater institutional rules and norms. Based on $\mathrm{KG}$ literature, $\mathrm{KE}$ is conceptualised as an intervention, an attempt to affect science-society relationships.

\section{Materials and methods}

We use a case study approach (Yin 2014) and investigate the context and perceptions of KE in two cases from Zanzibar, Tanzania, East Africa. In both cases, the KE intervention was run by a Swedish-based researcher engaging with fishers in local communities to feed back the results from their research. The two interventions were of different kinds that we refer to as community dialogue and science outreach. We used qualitative semi-structured interviews and participant observation. Qualitative methods have been used to study different knowledge-related processes as they enable gaining an in-depth and rich picture of societal dynamics and decision-making processes (e.g. Ballard et al. 2008; Taylor and de Loë 2012). We applied an ethnographic approach in the qualitative data collection, in the sense that we also observed behaviour, listened to conversations between others and asked questions outside the set interviews, which 
Table 1 Definitions and use of legitimacy, credibility, relevance, salience and accessibility in knowledge exchange, knowledge systems and knowledge governance literatures

\begin{tabular}{|c|c|c|c|}
\hline Field of literature & Knowledge exchange (KE) & Knowledge systems (KS) & $\begin{array}{l}\text { Knowledge Governance } \\
(\mathrm{KG})\end{array}$ \\
\hline Author & Contandriopoulus et al. (2010) & Cash et al. (2003) & $\begin{array}{l}\text { Kerkhof and Pilbeam (2017) based on } \\
\text { Cash et al. (2003) }\end{array}$ \\
\hline Legitimacy & $\begin{array}{l}\text { Legitimacy is defined as the credibility } \\
\text { of information. Credibility is not } \\
\text { included as an independent concept }\end{array}$ & $\begin{array}{l}\text { Legitimacy is perception that the } \\
\text { production of information and } \\
\text { technology has been respectful of } \\
\text { stakeholders' divergent values and } \\
\text { beliefs, unbiased in its conduct and } \\
\text { fair in its treatment of opposing views } \\
\text { and interests }\end{array}$ & $\begin{array}{l}\text { Where there are different concepts of } \\
\text { public good or desired outcomes, } \\
\text { whose dominates? Do science-based } \\
\text { decision-making processes reinforce } \\
\text { existing power relations, or challenge } \\
\text { them? How do societal expecta- } \\
\text { tions of objectivity affect the role of } \\
\text { science in decision making? Does } \\
\text { science have a role in mediating } \\
\text { conflicting societal views? }\end{array}$ \\
\hline Credibility & & $\begin{array}{l}\text { Credibility refers to scientific adequacy } \\
\text { of the technical evidence and argu- } \\
\text { ments }\end{array}$ & $\begin{array}{l}\text { Whose knowledge, or what kinds of } \\
\text { knowledge, tends to be most readily } \\
\text { accepted by decision-makers? What } \\
\text { is the role of participation in support- } \\
\text { ing credibility? Does science-based } \\
\text { knowledge have a role in formal } \\
\text { accountability processes? Are there } \\
\text { multiple accountabilities? }\end{array}$ \\
\hline Relevance/Salience & $\begin{array}{l}\text { Relevance is timeliness, salience and } \\
\text { actionability of knowledge. Heavily } \\
\text { context dependent }\end{array}$ & $\begin{array}{l}\text { Salience is relevance of the assessment } \\
\text { to the needs of decision makers }\end{array}$ & $\begin{array}{l}\text { How visible are the knowledge-based } \\
\text { needs of decision makers } \\
\text { to researchers? What processes enable } \\
\text { this visibility? Whose } \\
\text { interests are included or excluded? }\end{array}$ \\
\hline Accessibility & $\begin{array}{l}\text { Includes dimensions such as formatting } \\
\text { and availability of knowledge }\end{array}$ & & \\
\hline
\end{tabular}

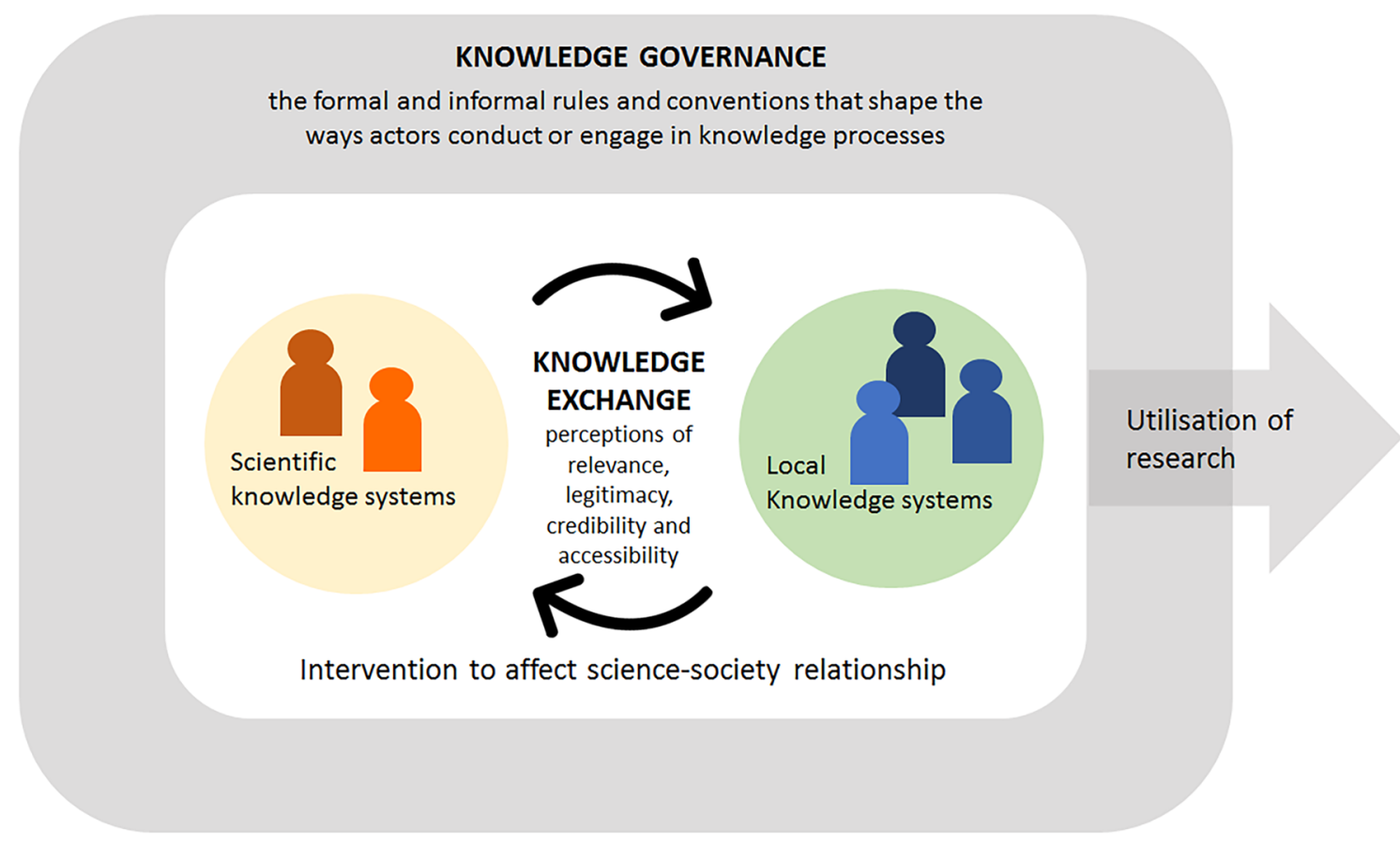

Fig. 1 Theoretical framework. Interactions between scientific and local knowledge systems as a knowledge exchange intervention are embedded in knowledge governance and use of knowledge is deter- mined by perceptions of relevance, legitimacy, credibility accessibility of new information. Not that each knowledge system is represented by persons that are the actors involved in the exchange 
Table 2 Summary of the workshop types

\begin{tabular}{|c|c|c|}
\hline Case & $\begin{array}{l}\text { Case 1: } \\
\text { Community dialogues }\end{array}$ & $\begin{array}{l}\text { Case 2: } \\
\text { Science outreach }\end{array}$ \\
\hline Topic of presented research & $\begin{array}{l}\text { Structure of the fisheries' value chain, including aspects of } \\
\text { gender differences, actors' aspiration to change, the role } \\
\text { of the tourism industry. Results from } 8 \text { sampling sites in } \\
\text { Zanzibar and } 15 \text { villages in the Philippines }\end{array}$ & $\begin{array}{l}\text { Perceptions of fishers, managers and researchers } \\
\text { of different management options for seagrass- } \\
\text { associated small-scale fisheries. Based on } 108 \\
\text { semi-structured interviews and open and closed } \\
\text { questioner questions with fishermen in } 7 \text { communi- } \\
\text { ties, } 8 \text { managers and } 5 \text { researchers in Zanzibar }\end{array}$ \\
\hline Workshop design & $\begin{array}{l}\text { A value chain 'map' depicting a typical fishery value chain } \\
\text { in Zanzibar functioned as a base for the workshop. The } \\
\text { researcher presented the information through data cards. } \\
\text { Each participant got a paper figure that presented them. } \\
\text { During the workshop, participants moved the figures in } \\
\text { the value chain map for example in the nodes (e.g. fisher, } \\
\text { trader, selling fish in urban/rural) they operate or would } \\
\text { like to operate. Questions were asked throughout the } \\
\text { workshop to hear participants' experiences and opinions. } \\
\text { Participants could comment and ask questions at any } \\
\text { moment }\end{array}$ & $\begin{array}{l}\text { Workshop was based on presentation of a poster that } \\
\text { presented the perceptions of different actors on } \\
\text { different management options including measures } \\
\text { such as education, temporary closures, no-take } \\
\text { zones, mesh size and gear restrictions and mini- } \\
\text { mum size of fish. Presentation was followed by an } \\
\text { open discussion. Participants could comment and } \\
\text { ask questions at any moment }\end{array}$ \\
\hline $\begin{array}{l}\text { Number of observed work- } \\
\text { shops and locations }\end{array}$ & $\begin{array}{l}7 \\
\text { Maruhubi, Mkokotoni, Nungwi, Uroa, Kizimkazi, Buyu } \\
\text { and Kizingo }\end{array}$ & $\begin{array}{l}3 \\
\text { Mkokotoni, Fukuchani, Kendwa }\end{array}$ \\
\hline Participants & $\begin{array}{l}\text { 11-20 participants } \\
\text { Fishermen and fisherwomen and men and women traders } \\
\text { (average ration } 1 / 4 \text { women participants, varying from } \\
0-50 \% \text { of participants) } \\
\text { Beach recorder present in } 5 / 7 \text { of the workshops }\end{array}$ & $\begin{array}{l}\text { 7-20 participants } \\
\text { Only fishermen (no women interviewed in the study) } \\
\text { Beach recorder present in all of the workshops }\end{array}$ \\
\hline
\end{tabular}

contributed to additional field notes and observation. We observed seven out of eight community dialogues and three out of seven science outreach workshops, since workshops were partly organised on the same days. Context interviews with range of actors were carried out before and after the workshops, and 1-3 participants were interviewed after each workshop. Thus, the sample per workshop is relatively small for inferring differences between workshops. Instead, results reflect the general experiences over the two different cases.

\section{Study site}

The two KE case studies concerned fisheries research and were conducted on Unguja Island in the administrative state of Zanzibar, located about $40 \mathrm{~km}$ off mainland Tanzania. In 1964, after over 70 years of British colonial rule, Zanzibar and mainland Tanganyika formed the United Republic of Tanzania. The population is mainly Kiswahili speaking and Muslim. Traditionally, the fisheries have provided an important livelihood and source of food and income to local communities (Lange and Jiddawi 2009). Expanding population, use of destructive gears and growth of the tourist industry have increased the pressure on marine resources, and management of fisheries has become more difficult (Jiddawi and Öhman 2003; Lange and Jiddawi 2009). The Department of Fisheries and Marine Resources (DFMR) is responsible for maintaining and protecting small-scale fisheries, monitoring fish stocks and encouraging sustainable fishing activity. Their management strategies cover gear restrictions, marine protected areas and limitations on fishing techniques (de la Torre-Castro 2006). Beach recorders (Bwana diko in Kiswahili) are appointed in in each village to monitor artisanal fishing and seaweed farming activities, record information on fishers such as gear use, enforce laws and serve as a communication channel for the DFMR (de la Torre-Castro 2006).

\section{Two cases of knowledge exchange}

The two studied cases of KE were organised and conducted by two European doctoral students (Table 2). The objective in both cases was to share research findings with the communities where the researchers had conducted research for their Ph.D. projects approximately three years earlier. The motive for the KE intervention was mainly ethical-a will to thank the communities and give something back to the participants in the research.

The two researchers used different approaches for their KE intervention. Case 1 used community dialogues approach. The workshops were implemented in an interactive manner where participants could share and validate their perceptions of shared information as part of the activities 
Table 3 Overview of the different data types and sample sizes

\begin{tabular}{ll}
\hline Type of data & Clarification \\
\hline Semi-structured interviews & $\begin{array}{l}\text { With local academics }(n=2) \text {, who work with fisheries research and external researchers, } \\
\text { beach recorders }(n=6), \\
\text { key informants in the small-scale fisheries (included } 3 \text { fishers, secretary of beach recorder/fisher, chair of fisheries } \\
\text { committee/fisher, secretary of traders' cooperative/trader, } n=7) \text {, were identified with help of beach recorder, } \\
\text { workshop participants (community dialogues } n=12 \text {, science out each } n=4) \text { who volunteered after the workshops, } \\
\text { external researchers }(n=2) \text { conducting fisheries related research in Zanzibar } \\
\text { 10 different KE workshops }(7 \text { community dialogues, } 3 \text { science outreach workshops) and one meeting with managers } \\
\text { were observed as an outside observer. Participant observation was conducted throughout the whole process of } \\
\text { planning and implementing KE, including the fieldwork period but also time before and after fieldwork } \\
\text { Two times with managers, first with 3 participants and then with 2. One manager participated in both discussions } \\
\text { Observation } \\
\text { Some landing sites (Uroa, Kizimkazi, Maruhubi, Nungwi and Mkokotoni) were visited three months after the work- } \\
\text { shops. Visits included discussions with some workshop participants such as beach recorders, fishers and traders } \\
\text { when they were reached }\end{array}$ \\
Informal follow-ups &
\end{tabular}

(Table 2). The aim of the intervention was to share the overall view of the fish value chain, as it had emerged in the research, to the fishers and traders. The researcher did not expect the results to be of direct practical use for the participants, as the research was designed for academia rather than end users, and no direct recommendations were presented. Case 2 can be described as science outreach workshops. In each workshop, a presentation of the researcher was followed by an open discussion (Table 2). The aim of this intervention was to provide the fishing communities that contributed to the research with a quantitative overview of what fishers thought about existing and other management options, as revealed in the research. The researchers in this case considered the research findings being more useful for the management level.

In both cases, the researchers designed and facilitated a workshop to reach community-level members who would not otherwise have easy access to scientific information such as scientific reports or publications. Participants were invited by the beach recorder of the respective landing site. The beach recorders were instructed either on phone or in a meeting in person to target the fishers and fish traders who had been interviewed for the Ph.D. projects. However, workshops were open for other fishers and traders to participate, and most participants had not participated in the research projects. For the community dialogues, the researcher asked beach recorders to encourage women fishers and traders to participate as the researcher knew that they would be harder to be reached. Women participated to varying degrees in community dialogues with half of the workshop participants being women at the highest and no women present at the lowest (Table 2). One of the observed community dialogue workshops included only traders and one only fishers. Otherwise the participants represented a mix of traders and fishers, and the exact division between occupations was not recorded. All the participants in science outreach workshops were fishermen since only that actor group had been included in the research project (Table 2).

In each workshop, up to 20 invited participants were given 2000 Tanzanian Shillings (0.9 USD) as a compensation for their participation. In community dialogues, they were also served snacks and soft drinks. However, the workshop was organised in public places such as on beaches, and were open for other curious people to come and leave freely during the workshops and, therefore, workshops reached actors beyond invited participants. The studied cases included communities where many researchers are advised by the local research institute to conduct their fisheries-related research.

\section{Qualitative data collection}

The majority of the data collection took place during a one-month field trip in Unguja Island November-December 2017. The first author conducted participant observation (Bernard 2006) in the KE workshops (7 Community Dialogues; 3 Science Outreach workshops) to capture the interactions between researchers and participants and among participants. She also observed the two researchers in each case, in their planning and execution of the KE process before and during the fieldwork period.

Semi-structured interviews were carried out in different sets: (i) two sets of semi-structured interviews, before and after the implementation of the workshops, with the external researchers; and (ii) context interviews with key informants, including local academics, beach recorders, fishers and traders, local officials and managers; (iii) postworkshop interviews with workshop participants (see more details in Table 3). Furthermore, there was an opportunity to visit some of the communities three months after workshops, which provided some additional informal observation of people's perceptions of the community dialogue workshops. 
For the semi-structured interviews, we used purposive sampling (Bernard 2006). In the context interviews, our purpose was to capture informants from important stakeholder groups, including beach recorders, local academics and management officials. In the workshop participant interviews, we interviewed participants who volunteered, and we could only reach people who stayed around after the workshops. We aimed at interviewing both women and men, and fishers and traders participating in each workshop (see supplementary material 1 for detailed information of sampling of interviewees).

We conducted interviews with local community members in Kiswahili with the help of translators. Interview guides were designed by the research team around the themes presented in the theoretical background of KE, KS and KG including topics such as legitimacy and trustworthiness of scientific information, information sources used in decision making and use of scientific knowledge in decision making (see Supplementary Material 2 for the different interview guides). The interview guide used after workshops was piloted with local students and with a participant of the first observed workshop. Other interview guides were modified according to important emerging topics during the fieldwork period.

\section{Data analysis}

We transcribed recorded interviews and digitalised notes from hand-written interviews, then thematically coded interviews with different code sets for the different research questions using qualitative data analysis software MAXQDA. The coding process was open to emerging themes not necessarily supported by the theoretical background (see Supplementary Material 3 for the coding structure). This can be referred to as abductive reasoning as the data analysis based on finding surprising empirical results against a background of existing theories (Timmermans and Tavory 2012). In addition to prominent themes, we focussed on more rare perspectives to map a wide range of experiences. Using data from different sources (interviews, observation and other field notes) helped to ensure validity of findings by triangulation (Bernard 2006) and diminished the risk for deference effect and social desirability bias (Bernard 2006; Denzin and Lincoln 2011). Hence, observation and informal discussions offered some more critical perspectives, which are also reflected in the results. The focal point of our analysis in this paper was interactions between external researchers and local actors. However, we acknowledge that interactions between local actors as well are essential in influencing KE and how it is experienced and, therefore, occasionally refer to these actor relationships.

\section{Results}

\section{Context for KE: patterns of interaction and flows of benefits}

This section describes the context in which KE processes took place in terms of interactions between researchers and different local actors, previous experiences of these interactions and perceptions of scientific knowledge.

We identified key actor groups and a set of interactions that form the context for KE. An overview is given in Fig. 2, which highlights parts of KG by presenting some of interactions between these actors manifested in flows of benefits. The knowledge governance context for fisheries research in Zanzibar depicts the flows of benefits between 6 key actor groups (a-f), and particularly to/from the external researchers (a). Key benefits flowing from external researchers to local actors include money, external contact and status (g-h). Key benefits flowing to external researchers include access for and facilitation of research and local knowledge and time participating in e.g. surveys $(i-j)$. The flow of scientific knowledge to benefit management and to feedback to local actors has been limited (k). These relationships create the fundamental base for foreign researchers conducting research projects in Zanzibar.

Benefits are closely related to power relationships. Table 4 presents benefits exchanged and aspects of power in the relationship between external researchers and local stakeholders. Ultimately, researchers directly benefit through gaining degrees, publications, and creating an academic career based on knowledge extracted from local actors. As shown in Table 4, we also highlight the benefits local stakeholders may gain from interaction with external researchers in the researched context. Few of these benefits are knowledge based. The local actors in turn shape the research process and thus have some power-yet maybe marginal—over the processes.

\section{Exploring perceptions of scientific knowledge and researchers at the community level}

Beach recorders and other key informant interviewees stated that they generally trusted researchers and their knowledge since they can validate researchers' information by what they see in the environment, or because the changes they see in the environment are explained by researchers [BD2, KI2, KI3, KI4, KI5 ${ }^{1}$ ]. Also, research was perceived

\footnotetext{
${ }^{1}$ Citation to the interviews. $\mathrm{KI}=$ Key Informant, $\mathrm{M}=$ Managers, $\mathrm{LA}=$ Local academic, $\mathrm{E}=$ External researcher, $\mathrm{BD}=\mathrm{Beach}$ recorder (Bwana Diko), 1WS=Workshop type 1 participant, $2 \mathrm{WS}=$ Workshop type 2 participant (see supplementary material 4 ).
} 


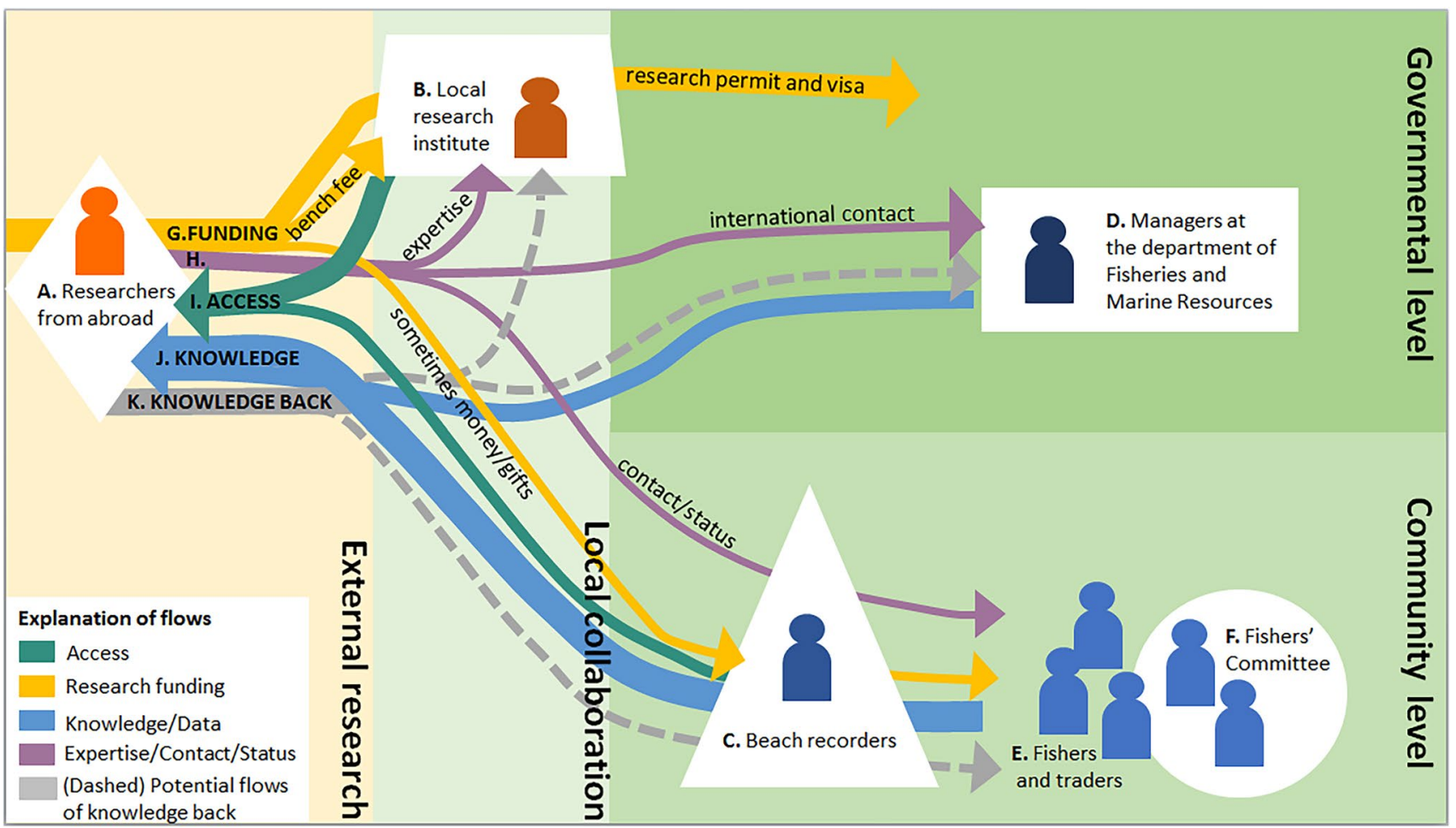

Fig. 2 Flows of benefits between external researchers and local actors. Funding for research projects is exchanged for access to research subjects. Sharing research findings with local actors is mostly missing. The figure was created based on interviews and field observation

trustworthy if it could be applied and was useful [BD4, KI4, KI5]. As noted by a few interviewees, this requires researchers sharing their results [BD1, BD6, KI1]. Research-based knowledge was considered useful in describing the system, increasing awareness, and providing knowledge about the environment and better ways to do fishing or trading activities [BD1, BD3, BD4, BD5, KI1, KI4]. Science was seen as having modern and technological aspects, which can offer more efficient or environmentally friendly ways to support livelihoods, compared to the local ways of practising activities [BD4, KI7, 1WS2, 1WS11]. Researchers were linked to possibilities for learning, creating solutions and exchanging ideas [BD1, BD2]. Some of the interviewees even hoped to have more contact or training with researchers [BD2, KI1, $\mathrm{KI} 3, \mathrm{KI} 5, \mathrm{KI} 7]$. Researchers were also seen to function as a link between local and other actors such as managers or NGOs which could lead to benefits to communities [KI3, $\mathrm{KI} 7]$.

\section{Signs of research fatigue}

Signs of research fatigue became evident through interviews. In most of the communities, fishers, traders and beach recorders generally recalled no researchers or only a few ever coming back to share their results in spite of "too many" researchers conducting research in their villages. Hence, some of the interviewed fishers and beach recorders felt that fishers did not get anything back from the interaction [BD3, BD6, KI6, KI7]. Simultaneously, students and researchers were considered to benefit from the interaction as they could collect data for their degrees [BD6, KI6].

External researchers and a local academic reported that in some communities researchers need to pay for the participation in research projects, or research cannot be conducted at all [E1, E2, L2]. One of the interviewed beach recorders described a change in people's attitudes with regard to payment:

They [fishers] are not tired [of participating in research projects]. They are really interested to have contact with the researchers. But nowadays, something has changed. They need something, like to get money. So, they become very happy that researchers are here with them.-Beach recorder [BD5]

The comment reflects a typical narrative regarding possible research fatigue: many times, interviewees insisted that people like to have contact with researchers but this was often conditional on getting something in return. Expectations of benefits were often expressed indirectly: frequently after interviews, interviewees asked for favours, or contact with "donors" or NGOs, rather than for direct compensation for the interview. 

exchange

The practise of KE was negotiated with, and shaped by, local actors with whom researchers had collaborative relationship such as the local research institute and beach recorders and their interests. This limited researchers' influence on the process. For example, accepting local research institute's guidelines regarding a compensation for participation in the workshops was necessary not to risk the collaborative relationships at the institutional level. Thus, both researchers did provide a small payment for participants, despite their initially negative views toward compensation. Hence, it is impossible to separate gaining material benefits from participants' experiences in the observed KE workshops.

The external researchers organised workshops with help from beach recorders. Beach recorders selected relevant participants to the workshops in exchange for payment. Therefore, beach recorders had a great role in deciding who has access to the information and other benefits. Often participants said that they came to the workshop because a beach recorder told them to participate or it was their "job" as fishers or traders. Access to the workshops had in some cases a social and political nature. For example, one fisherman explained he never gets information about events as he does not support the ruling political party, while a woman trader admitted that she had been invited due to her close relationships to a beach recorder.

In the studied cases, accessibility of knowledge becomes a key issue for the context of KE and in turn for perceptions of it in three ways (i) the lack of general feedback from different previous research encounters, (ii) feeling of not getting anything back from constant participation in research projects and (iii) where access to research findings and other benefits was possible, it was mediated by social and political relations.

\section{Experiences about the two cases of knowledge exchange}

Based on the lack of sharing research findings back to the researched context described above, the novelty of a researcher coming back and sharing research findings was evident in both types of workshops. Many times, interviewed workshop participants mentioned they either learned that researchers can come back or that researchers can come back was the most surprising information in the workshops [1WS: $3,8,9,11 ; 2 \mathrm{WS} 3]$. The researchers described how they felt gratefulness from the communities for coming back, and they were surprised that in most of the cases people were keen on participating. The following sections shed light on perceptions of relevance, legitimacy and credibility of the observed KE processes. 


\section{Relevance and learning}

\section{Relevance and learning in the community dialogue}

KE There was a variation in what participation in the workshops meant to the participants. It was seen to provide learning and results but also contact with researchers [1WS: 1, 2, $3,5,7,8,11,12]$, as well as assurance that other people outside Zanzibar know about the fisherfolks' situation [1WS: $9,12]$. Receiving material benefits was also mentioned once [1WS12]. A trader's comment combines many of these aspects:

I think that now there is some kind of connection. Because researchers came to see us... it is very very important to us. And learning about other people like in other countries, doing the same activities, is very useful for us. And also, we can take the information and tell each other: "We are very important because other people know about us", and even when other researchers come here sit together like this, it is very important.-Male trader, Maruhubi [1WS11]

The content of the comment shows that KE can make participants feel acknowledged, hinting towards empowerment, as participants see that people from outside Zanzibar are interested in their situation. This can be subtle and surprising from a researcher perspective-probably often underestimated or not understood. Also, an interesting aspect for many interviewed participants was to learn about small-scale fisheries in the Philippines as compared to Zanzibari context [1WS: 4, 6, 7, 9, 11, 12]. For example, a female trader described how hearing that women in the Philippines do deep-sea fishing made her aware that it is also possible for women. However, it was difficult for some interviewees to describe learning or new and surprising information from the workshop. For example, a male trader described the output of the workshop vaguely as "learning about how to trade and fish", and when asked about reasons to participate he explained how he is one of those who like to participate in the events and to be close to visitors. KE is thus not linked only to sharing knowledge but there are other interests playing out within interactions with researchers. These can be financial or even simply having a good feeling from the interaction or being curious about visitors.

Interviewees often related presented information to ways to do business, such as learning that there are possibilities to export fish or connect to the tourism industry, suggesting that some participants had a limited understanding of the value chain beyond their own node of operation. The researcher did not provide advice about more profitable or sustainable business models. Nevertheless, we found that participants often created an action-oriented meaning for themselves, saying that they had learned different ways of doing business that could be better or more profitable [1WS:1, 2, 5, 6, 7,
$8,12]$. For example, a fisherman described how he is now excited about trying to sell his catch outside the landing site:

Earlier I thought of selling fish to anyone in the village but now I am happy to sell my fish to someone else through deals and trust throughout the action. [...] The thing that entered to my brain is to sell our fish through someone else, not here to local consumers like I did. I got excited to sell fish outside [the village].-Fisherman, Buyu [1WS8]

This perception about how to sell fish emerged from the exchange between participants as they discussed a lot about the topic in the workshop. Sometimes these unpredictable 'created meanings' (how information was discussed between participants) were even conflicting with what the researcher wanted to communicate, which was frustrating for the researcher [E1]. Nevertheless, changing the way to do daily activities was seen as impossible by many of the interviewees due to lack of money and resources although the gained information was described as useful [1WS:1, 2, $6,7,8,9]$. The lack of material or other assets to act upon information created a barrier to apply new knowledge or perceived meanings into action, which led two fishermen in one workshop to question the purpose of KE. In one landings site, a change based on shared knowledge was detected three months after workshops in the form of a new trade connection to the mainland. According to the beach recorder of the site, information presented in the workshop about different trade connections in Unguja had given the idea for the new way of selling fish.

Relevance and learning in the science outreach KE The science outreach workshops presented information about fishers' perceptions of management options, and the researcher made it clear to participants that she would communicate the same results to the fisheries managers. Hence, participants' perceptions of the workshops and the information were related to the role of the researcher as a knowledge broker between communities and managers. The usefulness of the knowledge was perceived as indirect, through management. The contact with the researcher also created an impression that fishers' voices were heard. For example, a fisherman described how he got a chance to share his ideas with somebody who could take his views to the decisionmakers [2WS3]. The perceived connection to managers was actively used in the workshops as fishers asked the researcher to communicate material needs such as boats or gears to the management level. This was uncomfortable for the researcher, who had hoped to focus more on the presented information [E2].

Linking to the management level through a researcher was seen as a way to hold decision-makers accountable [2WS 2, 3, 4] and affect the power relations between them. 
For example, one fisherman described how fishers are like bosses to the managers, while another said:

It is very important for the department to know [about the research findings], because this will influence their accountability. Because now everybody knows, because after research [has been conducted] we [fishers] have results. So, we have evidence, we have reference. The researcher has done research and these are the results and they are sent to the department. "Why did you not implement according to these results", fishers can ask. "We agreed that. The results are correct and you received it from the researcher, and other experts." So, this will influence the accountability of the staff at the Department, because we know. Even fishers, we know results. Managers think: "If I don't implement this I will be in trouble."-Fisherman, Kendwa [2WS4]

\section{Credibility and legitimacy}

Perceptions of credibility of information were investigated for both KE processes through a sense of trustworthiness. Most interviewed participants said they trusted the presented information, and nothing was misunderstood by the researchers. However, one woman trader expressed reservations that the information could not be into action. Perhaps because the research was based on interviews, hardly any information conflicted with what the participants already knew, which may have contributed to legitimacy and credibility. Perceiving information as legitimate and having a feeling of ownership over it may contribute to sharing it with others, as a trader commented "there is no problems in sharing this information [with others] as it comes from traders" [1WS11].

\section{Discussion}

The two case studies of KE processes illustrate three broad findings about KE. Firstly, the process, outcomes and perception of $\mathrm{KE}$ are determined by the context, including the pre-existing relationships and structures between a range of actors. Secondly, the incentives and outcomes of KE are not solely about knowledge; they also involve the exchange of material and other intangible resources and can influence power relations. Finally, and perhaps as a consequence of the first two, the outcomes of KE are unpredictable and external researchers have limited control over them. This reflects the complex nature of $\mathrm{KE}$ recognised in the literature (Cvitanovic et al. 2015b; Fazey et al. 2014). There is a growing notion of the complex sets of engagements and relationships that are a part of KE processes. These develop over time in science-society interactions, emphasising the interdependency and interrelatedness of actors, who operate in the contexts of institutional norms and values (Contandriopoulos et al. 2010; Cvitanovic et al. 2015b; Roux et al. 2006; Vogel et al. 2007). Complexity of outcomes of KE reflects the nature of the context, where different knowledge systems, multiple actors and incentives shape the way that research is conducted, shared and used. Therefore, understanding the $\mathrm{KG}$ context becomes crucial also in unpacking KE.

\section{Science-society relationship embedded in previous research encounters and actor relationships}

Our results highlight the influence of previous research encounters on KE through both the lack of flows of knowledge back to communities and general research fatigue among fishers and traders in Zanzibar. As Toomey (2016) shows, the impact researchers have on their field sites is not linear but embedded in different encounters between researchers and stakeholders before, during and after the fieldwork, where different power relations shape the interactions. The two cases of KE were welcomed at the community level due to limited feedback from previous research. The presence of researchers in wider socio-political context, such as community meetings, can build trust and help communicating knowledge (Young et al. 2016b). Similarly, here, the primary effects of KE can be seen as improving science-society relationships by counteracting research fatigue. Feelings of being over-researched can stem from a lack of perceived improvements, indifference toward engagement or practical issues such as cost, time and organisation, or extractive nature of research or lack of feeling an ownership over the project (Clark 2008). Thus, while sharing findings with researched communities may address the perceived lack of feedback, it cannot address long-term feelings of over-research if findings are not perceived as actionable for example due to lack of resources or because they do not lead to improvements.

Institutional relationships related to organising KE workshops were particularly influential in $\mathrm{KE}$ at the community level. Collaboration with the local research institute and beach recorders directly shaped the workshop design (e.g. participants were paid) or actors' access to the presented information (who was invited by the beach recorders and how well communities were informed about the workshops), restricting researchers' authority over the process. The local research institute and beach recorders were gatekeepers to the field, who gave access to logistical, human, institutional or informational resources in the field, a common phenomenon in fieldwork as discussed by Campbell et al. (2010). Understanding how different types of relationships support or constrain KE could inform more efficient KE implementation. 


\section{Knowledge-based outcomes}

Our study demonstrates tensions in knowledge-based outcomes between what was expected by the researchers and how shared knowledge was perceived by the local actors. Neither researcher expected the knowledge to be directly usable at the community level nor for changes in practice or understandings to result. However, KE, particularly in the community dialogues, led to general enlightenment (conceptual use of research). Such enlightenment included for example seeing new possibilities in fish trading such as learning that fish can be exported outside Zanzibar or considering that selling fish through a trader would be more beneficial for one's business. Conceptual use of research can lead to action indirectly and less specifically than if information was used instrumentally (Beyer 1997). The encounters of KE were not tailored to fit to specific needs in the specific situations, and thus according to Beyer (1997), the instrumental use of information by stakeholders cannot be expected. However, Rudd (2011) argues that due to the pervasive nature of conceptual use of research, instrumental impacts are dependent on conceptual impacts. Conceptual impacts can turn into instrumental use of research at later stages, for example if resources become available (Wall et al. 2017). In our cases, researchers did not share knowledge in an instrumental form, but it was instrumentalised by participants based on their existing knowledge and worldviews. Hence, recommendations for business strategies were created by participants through their meaning-making out of information.

According to Nonaka et al. (2000), "information becomes knowledge when it is interpreted by individuals and given a context and anchored in the beliefs and commitments of individuals". The knowledge creation process is thus context specific as it depends on who participates and how they participate (Nonaka et al. 2000). This demonstrates the difficulties in KE between different knowledge systems, as knowledge is embedded in individuals' perceptions and worldviews (Evely et al. 2011), and use of new knowledge depends on how well new information fits for the needs of users (Lemos and Morehouse 2005). Knowledge itself and unpredictability of its creation are a part of the complexity of the phenomenon. Therefore, viewing knowledge as an open, socially and ecological embodied system (Tàbara and Chabay 2013) can also support understanding dynamics of $\mathrm{KE}$ as it acknowledges and embraces the complexity, compared to more reductionist worldviews on knowledge. Consequently, sustainability scientists should expect unpredictable meaning-making as an outcome of KE. As pointed out by Evely et al. (2011), increased communication between actors and KE is not a simple "panacea" to reach sustainable outcomes. Combining different knowledge systems is a difficult process (Berkes 2009), and different understandings of presented information and what was wanted to be communicated could create varying, possibly socially or environmentally undesirable outcomes.

On the contrary, although the presented information was described as useful by many interviewees, and even though it met principles of relevance, legitimacy, credibility and accessibility, it was not necessarily actually usable due to constraints or barriers. This finding calls for more attention to understanding actionability in community-level contexts where actors can lack social, material or political assets to act upon the knowledge, and hence usability of knowledge is limited. Actionability is not only linked to the type of knowledge but to conditions where knowledge is received, as the case study shows: Often in the community dialogues, the possible action stemming from interpretation of information was prohibited by a lack of material assets. However, focusing only on usable knowledge for sustainable development (e.g. Clark et al. 2016) can lead to missing the possible importance of non-actionable information for the stakeholders. For example, information about the Philippines was described as interesting and useful, which reflects that knowledge for the sake of gaining new perspectives can be equally or even more valuable than directly usable knowledge.

\section{Researcher as knowledge provider, facilitator or broker?}

The multiple and varying roles of researchers are increasingly recognised in sustainability science (e.g. Wittmayer and Schäpke 2014). Our findings show how researchers adopted different roles during the KE processes. One of the observed effects of KE in the community dialogues was the creation of a setting for exchange between local participants, where fishers and traders interacted and discussed about their livelihoods. The role of the researcher was then a facilitator of a dialogue that enabled a space for learning. Instead, in the science outreach workshops, fishers hoped that receiving research findings could contribute to the involvement of fishers' views in management. The researcher was thus perceived rather as a broker of knowledge to mediate different views between fishers and managers. The roles can even be adopted unintentionally and different actors in KE process can have different perceptions on researchers' positions, which in turn have implication on how KE is perceived. Hence, in both cases, researchers found themselves stretched beyond their expected roles of knowledge providers. Therefore, awareness of the socio-political context as proposed in the literature about KG (van Kekhof and Pilbeam 2017) enables designing KE strategies which acknowledge the roles and spaces that researchers possibly fill and create when they engage in KE. 


\section{Beyond knowledge-based outcomes: multidimensional interactions with researchers}

Participation in research-related projects is led by multiple interests that impact the possible outcomes of encounters. Previous literature about KE has not taken into account nonknowledge-based aspects and assets, which were an important part of these KE cases and their outcomes (Fig. 2). Focusing only on usable knowledge can lead to simplifications of the context and a naïve understanding of the motivations of actors in the KE and research spheres. At the community level, researchers provided (i) knowledge and training, (ii) material benefits, (iii) contact and assistance to reach other actors and (iv) status in the community. They also exchange in reciprocal relationships with national institutions and local gatekeepers, exchanging money, status and international connectivity for access and practical research opportunities (Table 4). Therefore, KE researchers, themselves have multiple incentives for implementation of KE, ranging, in the case study, from ethical responsibilities and personal obligation toward people encountered in the field to an aim to have a real-world impact.

This study focused on one aspect of KE in the form of sharing of research findings. Our case studies covered relatively conventionally designed research processes where KE was included in the end of the projects. Although KE is advocated in the early phases of a research project through co-productive approaches (e.g. Phillipson et al. 2012), in practice research projects often lack formalised plans to engaging end-users throughout the research process (Wall et al. 2017). Therefore, this article can provide useful insights into many research processes that do not involve longer-term stakeholder engagement throughout a research project.

Our explorative approach to data collection would have benefitted from a longer fieldwork period that would have enabled a more detailed mapping of local actors' relationships and a more profound understanding of power dynamics. Benefits and patterns of interactions manifested in $\mathrm{KE}$ are related to power relations, which could be further explored through an explicit power analysis. We suggest power analysis as key for future studies of KE, particularly in the Global South but also in the Global North.

\section{Conclusions}

Our analysis of the two KE processes between foreign researchers in Zanzibari fisheries highlights some key aspects of KE. Firstly, KE is shaped by previous experiences of research and the pre-existing relationships between research actors. In these cases, research fatigue and a lack of feedback meant that KE was welcomed as a departure from typical practises, while institutional relations created constraints on where, with whom and how KE occurred. Secondly, the process by which knowledge becomes instrumentalised as a result of $\mathrm{KE}$ is unpredictable and sometimes uncomfortable for researchers. For example it may facilitate new forms of exploitation of natural resources. Thirdly, KE involves researchers playing multiple roles including knowledge broker, facilitator of interactions between local actors as well as knowledge producer. Lastly, KE involves exchange of benefits between researchers, local institutions and community members. These include non-knowledge assets such as material benefits, prestige and strengthening of voices to authorities. These exchanges are based on pre-existing relationships, in which different stakeholders negotiate their interests according to different sources of power. In conclusion, a better understanding of the relationships between researchers, local institutions, research subjects and potential knowledge users, including their interests in non-knowledge assets and relative power exchanges can help can help to navigate the complexity of KE.

Acknowledgements Most importantly we want to thank all the participants for sharing their time and knowledge. Open access funding provided by Stockholm University and funding for the fieldwork by Stockholm Resilience Centre.

Open Access This article is distributed under the terms of the Creative Commons Attribution 4.0 International License (http://creativeco mmons.org/licenses/by/4.0/), which permits unrestricted use, distribution, and reproduction in any medium, provided you give appropriate credit to the original author(s) and the source, provide a link to the Creative Commons license, and indicate if changes were made.

\section{References}

Agrawal A (1995) Dismantling the divide between indigenous and scientific knowledge. Dev Chang 26(3):413-439. https://doi. org/10.1111/j.1467-7660.1995.tb00560.x

Bäckstrand K (2003) Civic science for sustainability: reframing the role of experts, policy-makers and citizens in environmental governance. Glob Environ Politics 3(4):24-41. https://doi. org/10.1162/152638003322757916

Ballard HL, Fernandez-Gimenez ME, Sturtevant VE (2008) Integration of local ecological knowledge and conventional science: a study of seven community-based forestry organizations in the USA. Ecol Soc. https://doi.org/10.5751/ES-02594-130237

Berkes F (2009) Evolution of co-management: Role of knowledge generation, bridging organizations and social learning. J Environ Manag 90(5):1692-1702. https://doi.org/10.1016/j.jenvm an.2008.12.001

Bernard HR (2006) Research methods in anthropology: qualitative and quantitative approaches, 4th edn. AltaMira Press, Lanham

Beyer JM (1997) Research utilization: bridging a cultural gap between communities. J Manag Inquir 6(1):17-22. https://doi. org/10.1177/1056492611432797

Boreux V, Born J, Lawes MJ (2009) Sharing ecological knowledge: opportunities and barriers to uptake. Biotropica 41(5):532-534. https://doi.org/10.1111/j.1744-7429.2009.00574.x 
Campbell LM, Gray NJ, Meletis ZA, Abbott JG, Silver JJ (2010) Gatekeepers and keymasters: dynamic relationships of access in geographical fieldwork. Geogr Rev 96(1):97-121. https://doi. org/10.1111/j.1931-0846.2006.tb00389.x

Cash DW, Clark WC, Alcock F, Dickson NM, Eckley N, Guston DH, Mitchell RB (2003) Knowledge systems for sustainable development. PNAS. https://doi.org/10.1063/1.4795010

Clark T (2008) “We're over-researched here!": exploring accounts of research fatigue within qualitative research engagements. Sociology 42(5):953-970. https://doi.org/10.1177/0038038508094573

Clark WC, van Kerkhoff L, Lebel L, Gallopin GC (2016) Crafting usable knowledge for sustainable development. Proc Natl Acad Sci 113(17):4570-4578. https://doi.org/10.1073/pnas.1601266113

Contandriopoulos D, Lemire M, Denis JL, Tremblay É (2010) Knowledge exchange processes in organizations and policy arenas: a narrative systematic review of the literature. Milbank Q 88(4):444-483. https://doi.org/10.111 1/j.1468-0009.2010.00608.x

Cook CN, Mascia MB, Schwartz MW, Possingham HP, Fuller RA (2013) Achieving conservation science that bridges the knowledge-action boundary. Conserv Biol 27(4):669-678. https://doi. org/10.1111/cobi.12050

Cornell S, Berkhout F, Tuinstra W, Tàbara JD, Jäger J, Chabay I, van Kerkhoff L (2013) Opening up knowledge systems for better responses to global environmental change. Environ Sci Policy 28:60-70. https://doi.org/10.1016/j.envsci.2012.11.008

Cote M, Nightingale AJ (2012) Resilience thinking meets social theory: situating social change in socio-ecological systems (SES) research. Prog Hum Geogr 36(4):475-489. https://doi. org/10.1177/0309132511425708

Cvitanovic C, Hobday AJ, Van Kerkhoff L, Marshall NA (2015a) Overcoming barriers to knowledge exchange for adaptive resource management; the perspectives of Australian marine scientists. Marine Policy 52:38-44. https://doi.org/10.1016/j.marpo 1.2014.10.026

Cvitanovic C, Hobday AJ, van Kerkhoff L, Wilson SK, Dobbs K, Marshall NA (2015b) Improving knowledge exchange among scientists and decision-makers to facilitate the adaptive governance of marine resources: a review of knowledge and research needs. Ocean Coast Manag 112:25-35. https://doi.org/10.1016/j.oceco aman.2015.05.002

Cvitanovic C, McDonald J, Hobday AJ (2016) From science to action: principles for undertaking environmental research that enables knowledge exchange and evidence-based decision-making. J Environ Manag 183:864-874. https://doi.org/10.1016/j.jenvm an.2016.09.038

de la Torre-Castro M (2006) Beyond regulations in fisheries management: the dilemmas of the "Beach Recorders" Bwana Dikos in Zanzibar Tanzania. Ecol Soc. https://doi.org/10.5751/ES-01876 $-110235$

Denzin NK, Lincoln YS (2011) The SAGE Handbook of Qualitative Research. SAGE, Thousand Oaks

Evely AC, Pinard M, Reed MS, Fazey I (2011) High levels of participation in conservation projects enhance learning. Conserv Lett 4(2):116-126. https://doi.org/10.1111/j.1755-263X.2010.00152.x

Fazey I, Bunse L, Msika J, Pinke M, Preedy K, Evely AC, Reed MS (2014) Evaluating knowledge exchange in interdisciplinary and multi-stakeholder research. Glob Environ Chang 25(1):204-220. https://doi.org/10.1016/j.gloenvcha.2013.12.012

Fazey I, Evely AC, Reed MS, Stringer LC, Kruijsen J, White PCL, Trevitt C (2013) Knowledge exchange: a review and research agenda for environmental management. Environ Conserv 40(1):19-36. https://doi.org/10.1017/S037689291200029X

Fazey I, Fazey JA, Fischer J, Sherren K, Warren J, Reed F, Noss RF (2007) Adaptive leverage capacity for and learning to learn as. Front Ecol Environ 5(7):375-380.
Folke C, Hahn T, Olsson P, Norberg J (2005) Adaptive governance of social-ecological systems. Annu Re Environ Resour 30:441-473. https://doi.org/10.1146/annurev.energy.30.050504.144511

Gallo LA, Marchelli P, Chauchard L, Gonzalez PeÑalba M (2009) Knowing and doing: research leading to action in the conservation of forest genetic diversity of patagonian temperate forests. Conserv Biol 23(4):895-898. https://doi.org/10.111 $1 / \mathrm{j} .1523-1739.2009 .01210 . \mathrm{x}$

Hoppers CO (2002) Indigenous knowledge and the integration of knowledge systems. New Africa Books, Claremont

Jacobson N (2007) Social epistemology: theory for the "fourth wave" of knowledge transfer and exchange research. Sci Commun 29(1):116-127. https://doi.org/10.1177/1075547007305166

Jiddawi NS, Öhman MC (2003) Marine fisheries in Tanzania. Ambio 31(7):518-527. https://doi.org/10.1579/0044-7447-31.7.518

Kirchhoff CJ, Carmen Lemos M, Dessai S (2013) Actionable knowledge for environmental decision making: broadening the usability of climate science. Annu Rev Environ Resour 38(1):393-414. https://doi.org/10.1146/annurev-environ-022112-112828

Lange GM, Jiddawi N (2009) Economic value of marine ecosystem services in Zanzibar: implications for marine conservation and sustainable development. Ocean Coast Manag 52(10):521-532. https://doi.org/10.1016/j.ocecoaman.2009.08.005

Lemos MC, Arnott JC, Ardoin NM, Baja K, Bednarek AT, Dewulf A, Wyborn C (2018) To co-produce or not to co-produce. Nat Sustain 1(12):722-724. https://doi.org/10.1038/s41893-018-0191-0

Lemos MC, Kirchhoff CJ, Ramprasad V (2012) Narrowing the climate information usability gap. Nat Clim Chang 2(11):789-794. https ://doi.org/10.1038/nclimate1614

Lemos MC, Morehouse BJ (2005) The co-production of science and policy in integrated climate assessments. Glob Environ Chang 15(1):57-68. https://doi.org/10.1016/j.gloenvcha.2004.09.004

Nguyen VM, Young N, Cooke SJ (2017) A roadmap for knowledge exchange and mobilization research in conservation and natural resource management. Conserv Biol 31(4):789-798. https://doi. org/10.1111/cobi.12857

Nguyen VM, Young N, Corriveau M, Hinch SG, Cooke SJ (2018) What is "usable" knowledge? Perceived barriers for integrating new knowledge into management of an iconic Canadian fishery. Can J Fish Aquat Sci 76(3):463-474. https://doi.org/10.1139/cjfas $-2017-0305$

Nonaka I, Toyama R, Konno N (2000) SECI, Ba and leadership: a unified model of dynamic knowledge creation. Long Range Plan 33:5-34. https://doi.org/10.1016/S0024-6301(99)00115-6

Phillipson J, Lowe P, Proctor A, Ruto E (2012) Stakeholder engagement and knowledge exchange in environmental research. J Environ Manag 95(1):56-65. https://doi.org/10.1016/j.jenvm an.2011.10.005

Raymond CM, Fazey I, Reed MS, Stringer LC, Robinson GM, Evely AC (2010) Integrating local and scientific knowledge for environmental management. J Environ Manag 91(8):1766-1777. https:// doi.org/10.1016/j.jenvman.2010.03.023

Reed MS, Stringer LC, Fazey I, Evely AC, Kruijsen JHJ (2014) Five principles for the practice of knowledge exchange in environmental management. J Environ Manag 146:337-345. https://doi. org/10.1016/j.jenvman.2014.07.021

Roux DJ, Rogers KH, Biggs HC, Ashton PJ, Sergeant A (2006) Bridging the science-management divide: moving from unidirectional knowledge transfer to knowledge interfacing and sharing. Ecol Soc 11(1):4

Rudd MA (2011) How Research-prioritization exercises affect conservation policy. Conserv Biol 25(5):860-866. https://doi.org/10.11 11/j.1523-1739.2011.01712.x

Singh GG, Tam J, Sisk TD, Klain SC, Mach ME, Martone RG, Chan KMA (2014) A more social science: barriers and incentives for 
scientists engaging in policy. Front Ecol Environ 12(3):161-166. https://doi.org/10.1890/130011

Tàbara JD, Chabay I (2013) Coupling human information and knowledge systems with social-ecological systems change: reframing research, education, and policy for sustainability. Environ Sci Policy 28:71-81. https://doi.org/10.1016/j.envsci.2012.11.005

Taylor B, de Loë RC (2012) Conceptualizations of local knowledge in collaborative environmental governance. Geoforum 43(6):12071217. https://doi.org/10.1016/j.geoforum.2012.03.007

Tengö M, Hill R, Malmer P, Raymond CM, Spierenburg M, Danielsen F, Folke C (2017) Weaving knowledge systems in IPBES, CBD and beyond-lessons learned for sustainability. Curr Opin Environ Sustain 26-27:17-25. https://doi.org/10.1016/j.cosus t.2016.12.005

Timmermans S, Tavory I (2012) Theory construction in qualitative research: from grounded theory to abductive analysis. Sociol Theory 30(3):167-186. https://doi.org/10.1177/0735275112457914

Toomey AH (2016) What happens at the gap between knowledge and practice? Spaces of encounter and misencounter between environmental scientists and local people. Ecol Soc. https://doi. org/10.5751/ES-08409-210228

Van Kerkhoff L (2014) Knowledge governance for sustainable development: a review. Chall Sustain 1:2 https://doi.org/10.12924/cis20 13.01020082

van Kerkhoff LE, Lebel L (2015) Coproductive capacities: rethinking science-governance relations in a diverse world. Ecol Soc. https ://doi.org/10.5751/ES-07188-200114

van Kerkhoff L, Lebel L (2006) Linking knowledge and action for sustainable development. Annu Rev Environ Resour 31(1):445-477. https://doi.org/10.1146/annurev.energy.31.102405.170850

van Kerkhoff L, Pilbeam V (2017) Understanding socio-cultural dimensions of environmental decision-making: a knowledge governance approach. Environ Sci Policy 73:29-37. https://doi.org/10.1016/j. envsci.2017.03.011
Vogel C, Moser SC, Kasperson RE, Dabelko GD (2007) Linking vulnerability, adaptation, and resilience science to practice: pathways, players, and partnerships. Glob Environ Chang 17(3-4):349-364. https://doi.org/10.1016/j.gloenvcha.2007.05.002

Wall TU, McNie E, Garfin GM (2017) Use-inspired science: making science usable by and useful to decision makers. Front Ecol Environ 15(10):551-559. https://doi.org/10.1002/fee.1735

West S, van Kerkhoff L, Wagenaar H (2019) Beyond "linking knowledge and action": towards a practice-based approach to transdisciplinary sustainability interventions. Policy Stud. https://doi. org/10.1080/01442872.2019.1618810

Wittmayer JM, Schäpke N (2014) Action, research and participation: roles of researchers in sustainability transitions. Sustain Sci 9(4):483-496. https://doi.org/10.1007/s11625-014-0258-4

Yin, R. (2014). Case study research: design and methods (5th ed.). Thousand Oaks.

Young N, Corriveau M, Nguyen VM, Cooke SJ, Hinch SG (2016a) How do potential knowledge users evaluate new claims about a contested resource? Problems of power and politics in knowledge exchange and mobilization. J Environ Manag 184:380-388. https ://doi.org/10.1016/j.jenvman.2016.10.006

Young N, Nguyen VM, Corriveau M, Cooke SJ, Hinch SG (2016b) Knowledge users' perspectives and advice on how to improve knowledge exchange and mobilization in the case of a co-managed fishery. Environ Sci Policy 66:170-178. https://doi.org/10.1016/j. envsci.2016.09.002

Publisher's Note Springer Nature remains neutral with regard to jurisdictional claims in published maps and institutional affiliations. 